\title{
HRTEM Observation of Metastable Phases in a Mg-15\%Gd-6.4\%Sc Alloy
}

\author{
Tokimasa Kawabata, Kenji Matsuda and Susumu Ikeno \\ Graduate School of Science and Engineering for Research, University of Toyama, Toyama 930-8555, Japan
}

The aging behavior of a ternary $\mathrm{Mg}-15 \% \mathrm{Gd}-6.4 \% \mathrm{Sc}$ (mass $\%$ ) alloy was examined by high-resolution transmission electron microscopy. During the first stage of age hardening of the alloy, a contrast corresponding to a precursor of the $\beta^{\prime \prime}$ phase was observed predominantly. The $\beta^{\prime \prime}$ and $\beta^{\prime}$ phases coexist in the second stage of hardening, up to the point of maximum hardness. In the over-aging stage, the spheroidal contrast of the $\beta^{\prime}$ phase became longer along the $\langle 1 \overline{1} 00\rangle_{\mathrm{Mg}}$ direction. The addition of $\mathrm{Sc}$ to the $\mathrm{Mg}-\mathrm{Gd}$ alloys is useful to clarify the precipitation behavior and contribution of the $\beta^{\prime \prime}$ and $\beta^{\prime}$ phases to age hardening, as indicated by the two stage in the early stage of aging. [doi:10.2320/matertrans.MC200922]

(Received August 21, 2009; Accepted November 30, 2009; Published January 25, 2010)

Keywords: magnesium gadolinium scandium alloy, age hardening, precipitate, high-resolution transmission electron microscopy

\section{Introduction}

Magnesium-rare earth alloys are known to have a high specific strength, and their strength at high temperatures is superior to that of the other magnesium alloys. ${ }^{1)}$ In particular, $\mathrm{Mg}-\mathrm{Gd}$ alloys exhibit remarkable age-hardening properties and display high strengths at high temperatures; ${ }^{2,3)}$ they also show typical age-hardening behavior with a remarkable increase in hardness in the second stage rather than the first stage among the early stage of aging. Negishi et al. ${ }^{4)}$ reported a relationship between the hardness and the microstructure of the $\mathrm{Mg}-\mathrm{Gd}-\mathrm{Nd}-\mathrm{Zr}$ alloy. Their transmission electron microscopy (TEM) studies showed that the second stage of hardening may be caused by precipitation of the $\beta^{\prime}$ phase and the first stage may be caused by the presence of the $\beta^{\prime \prime}$ phase.

Vostry et al. ${ }^{5)}$ investigated precipitation in an isochronally heat-treated $\mathrm{Mg}-\mathrm{Gd}$ alloy by means of hardness testing, electrical resistivity measurements and TEM. They suggested that the supersaturated solid solution of $\alpha^{\prime}-\mathrm{Mg}$ successively decomposes during isochronal annealing at 20 to $500^{\circ} \mathrm{C}$ into the following phases: $\beta^{\prime \prime}\left(\mathrm{D}_{19}\right)$ metastable $\rightarrow \beta^{\prime}$ (c-b.c.o.) metastable $\rightarrow \beta\left(\mathrm{Mg}_{5} \mathrm{Gd}\right)$.

We previously made a detailed investigation of precipitation in the aged $\mathrm{Mg}-12 \% \mathrm{Gd}-1.9 \% \mathrm{Y}-0.7 \% \mathrm{Zr}$ and $\mathrm{Mg}-$ $8.3 \% \mathrm{Gd}-3.7 \% \mathrm{Y}-0.76 \% \mathrm{Zr}$ alloys by means of hardness testing, TEM and high-resolution TEM (HRTEM) observations. ${ }^{6,7)}$ We concluded that the $\beta^{\prime \prime}$ and $\beta^{\prime}$ phases coexisted on monolayers of $\mathrm{Gd}$ and $\mathrm{Y}$ on $\{1 \overline{1} 00\}_{\mathrm{Mg}}$ planes during the first stage of hardening, and the remarkable increase in hardness in the second stage was caused mainly by the presence of the $\beta^{\prime}$ phase.

Mordike et al. ${ }^{8)}$ reported that binary $\mathrm{Mg}-\mathrm{Sc}$ alloys (1019 mass\%), as a result of an almost complete absence of precipitation, show negligible age hardening and that their minimum creep rate decreases with increasing Sc content. The addition of $\mathrm{Mn}(\sim 1$ mass $\%)$ to $\mathrm{Mg}-\mathrm{Sc}$ alloys containing up to 15 mass \% of Sc improves the creep resistance due to the formation of a densely dispersed fine particles of the $\mathrm{Mn}_{2} \mathrm{Sc}$ phase that is stable at temperatures up to $573 \mathrm{~K}$. Stulikova et $a l .{ }^{9)}$ reported that in the $\mathrm{Mg}-\mathrm{Gd}-\mathrm{Sc}-\mathrm{Mn}$ alloy with low Sc content (0.91 mass\%), a complicated precipitation process involving precipitation of fine $\mathrm{Mn}_{2} \mathrm{Sc}$ particles, the $\mathrm{Mn}$ - and Gd-containing phases, and the metastable $\beta^{\prime}$ phase is responsible for the superior creep resistance and peak agehardening at elevated temperatures. However, the age hardening and precipitation behavior of ternary $\mathrm{Mg}-\mathrm{Gd}-\mathrm{Sc}$ alloys without Mn has not been investigated previously, although it is important to clarify the effects of addition of Sc on the agehardening and precipitation behaviors of the $\mathrm{Mg}-\mathrm{Gd}$ alloy.

In the present work, we made TEM and HRTEM observations to clarify the microstructures of precipitates in the ternary $\mathrm{Mg}-\mathrm{Gd}-\mathrm{Sc}$ alloy aged at $473 \mathrm{~K}$, and we propose a relationship between the hardness and the presence of a metastable phase.

\section{Experimental Procedure}

The chemical composition of the experimental alloy was $\mathrm{Mg}-15$ mass\%Gd-6.4 mass\%Sc. An alloy ingot was homogenized at $773 \mathrm{~K}$ for $57.6 \mathrm{ks}$, hot rolled at $773 \mathrm{~K}$ under an argon atmosphere, and then cold rolled to a thickness of $0.7 \mathrm{~mm}$. Specimens were encapsulated in Pyrex glass tubes under argon. The specimens were then solution treated at $773 \mathrm{~K}$ for $3.6 \mathrm{ks}$, quenched in chilled water, and aged in a silicone oil bath at $473 \mathrm{~K}$. The hardness was measured by using a Micro Vickers hardness tester. Specimens for TEM were thinned by twin-jet electro polishing in a mixture of 1 part of concentrated perchloric acid and 4 parts ethanol as the electrolyte at about $243 \mathrm{~K}$. TEM and HRTEM observations were performed by using an EM-002B transmission electron microscope (Topcon Co., Ltd., Japan) operated at $120 \mathrm{kV}$.

\section{Results and Discussion}

Figure 1 shows the age-hardening curve for a specimen aged at $473 \mathrm{~K}$; this shows that the alloy displays a two-stage behavior. Henceforth, these stages are referred to as the first and second stages. Figures 2(a) and 2(b) show a bright-field image and the corresponding selected area electron diffraction pattern (SAEDP) for the specimen aged at $473 \mathrm{~K}$ for $57.6 \mathrm{ks}$. Indistinct contrasts of precipitates were observed in Fig. 2(a). Diffuse spots can be seen between the $01 \overline{1} 0_{\mathrm{Mg}}$ and $1010_{\mathrm{Mg}}$ reflections in Fig. 2(b), and the positions of these spots correspond to the $\beta^{\prime \prime}$ phase with the hexagonal 


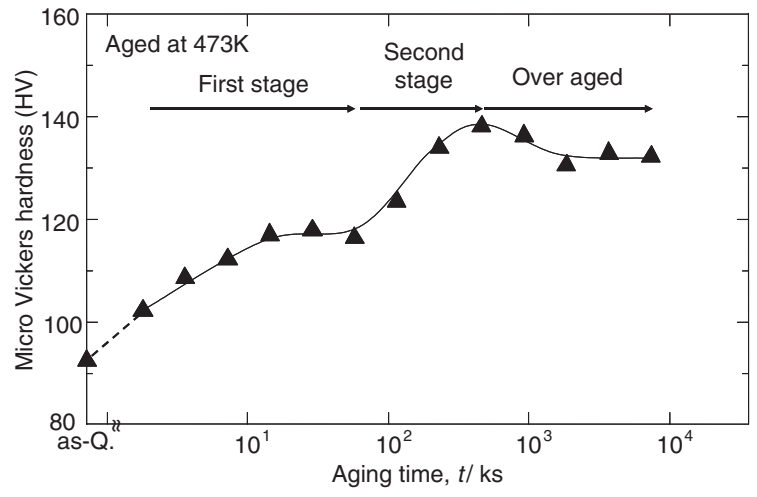

Fig. 1 Hardening curve for the specimen aged at $473 \mathrm{~K}$.

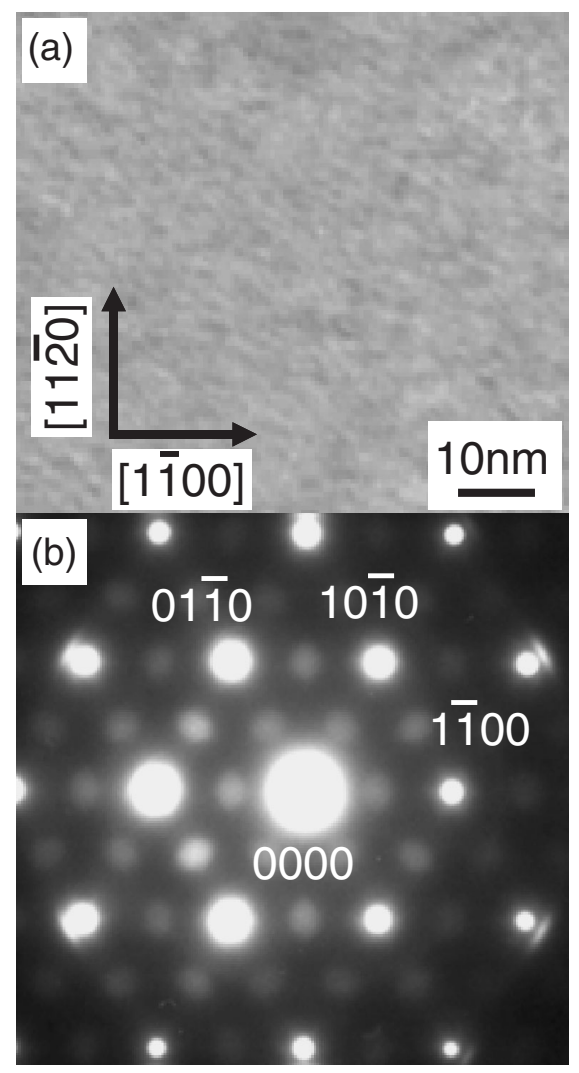

Fig. 2 TEM images of the specimen aged for $57.6 \mathrm{ks}$ at $473 \mathrm{~K}$ : (a) brightfield image and (b) SAED pattern.

$\mathrm{D}_{19}$ type ordered structure $(a=0.641 \mathrm{~nm}, c=0.521 \mathrm{~nm}$, $\left.[0001]_{\mathrm{Mg}} / /[0001]_{\beta^{\prime \prime}},\{2 \overline{1} \overline{1} 0\}_{\mathrm{Mg}} / /\{2 \overline{1} \overline{1} 0\}_{\beta^{\prime \prime}}\right)$, as previously reported $^{5)}$ for the $\mathrm{Mg}-\mathrm{Gd}$ alloy. Because it was difficult to observe the $\beta^{\prime \prime}$ phase in the bright-field image at low magnifications as a result of its close coherence with the magnesium matrix, ${ }^{10)}$ careful observations by HRTEM were carried out to confirm the existence of the $\beta^{\prime \prime}$ phase. Figure 3 shows the HRTEM image of the specimen aged at $473 \mathrm{~K}$ for $57.6 \mathrm{ks}$. Contrasts between three rows are apparent and these are indicated by arrows in the figure. The contrast between these rows is about $2 \mathrm{~nm}$ long, and bright and dark dots with a spacing of $0.32 \mathrm{~nm}$ are arrayed in a row along the $(1 \overline{1} 00)_{\mathrm{Mg}}$ plane. The arrangement of the bright and dark dots is that of a hexagon with sides $0.64 \mathrm{~nm}$ long, as indicated by the dashed line in the figure. This length of the sides corresponds to the

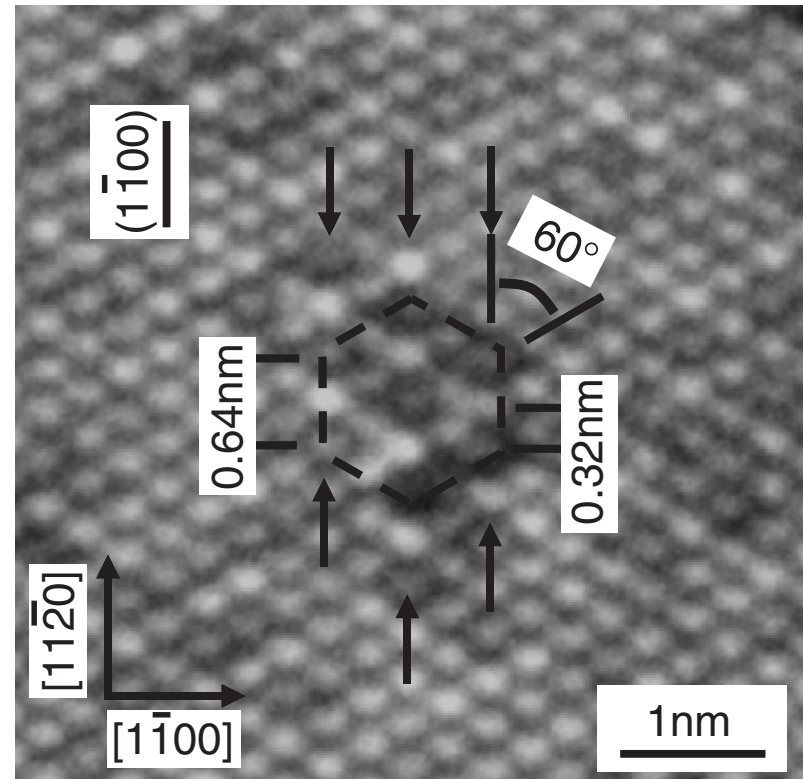

Fig. 3 HRTEM image of the specimen aged for $57.6 \mathrm{ks}$ at $473 \mathrm{~K}$. The arrows show the three rows along the $(1 \overline{1} 00)_{\mathrm{Mg}}$ planes. The arrangement of bright dots is indicated by solid dotted lines.

lattice parameter $a$ of the $\beta^{\prime \prime}$ phase. We regard this contrast, with its hexagonal arrangement of bright and dark dots with a spacing of $0.64 \mathrm{~nm}$, to show the presence of a precursor of the $\beta^{\prime \prime}$ phase, which has the lack of a complete hexagonal $\mathrm{D}_{19}$ type ordered structure because of the scattered spots corresponding to the precursor in Fig. 2(b). This precursor probably contributes to the increase in hardness during the first stage of hardening. At this stage, the $\beta^{\prime}$ phase could barely be seen. It has been reported that the $\beta^{\prime \prime}$ and $\beta^{\prime}$ phases coexist in the first stage of hardening for $\mathrm{Mg}-\mathrm{Gd}-\mathrm{Y}-\mathrm{Zr}$ alloys, ${ }^{6,7)}$ but the $\beta^{\prime}$ phase did not coexist with the $\beta^{\prime \prime}$ phase at the corresponding stage in the present alloy. We have therefore demonstrated that this is a particular feature of precipitation in the present alloy. It is suggested that the influence of Sc addition to $\mathrm{Mg}-\mathrm{Gd}$ alloys is to slow down the transformation from the $\beta^{\prime \prime}$ phase to the $\beta^{\prime}$ phase or stabilize the $\beta^{\prime \prime}$ phase.

Figures 4(a) and 4(b) are the bright field images and the SAEDP, respectively, for the specimen aged at $473 \mathrm{~K}$ for $460.8 \mathrm{ks}$, the length of aging that gave the peak hardness. There are many contrasts in Fig. 4(a) and these are similar to those for the nearly spherical precipitates in the $\mathrm{Mg}-\mathrm{Gd}-\mathrm{Zr}$ alloy aged at $523 \mathrm{~K}$ for $0.5 \mathrm{~h}$, as previously reported by Gao et al. ${ }^{10)}$ They identified an array of internal fringes with a spacing of about $1.1 \mathrm{~nm}$, which corresponded well to the spacing of $(020)_{\beta^{\prime}}$. In Fig. 4(b), a group of small five spots can be seen between the $01 \overline{1} 0_{\mathrm{Mg}}$ and the $10 \overline{1} 0_{\mathrm{Mg}}$ reflections (as indicated by the dashed circle), and other small spots can also be seen at one-quarter and three-quarters of the distance between the $01 \overline{1} 0_{\mathrm{Mg}}$ and $10 \overline{1} 0_{\mathrm{Mg}}$ reflections, which indicates the formation of the $\beta^{\prime}$ phase. This result is similar to that of Gao et al. ${ }^{10)}$ who reported that the spots halfway between the $01 \overline{1} 0_{\mathrm{Mg}}$ and $10 \overline{1} 0_{\mathrm{Mg}}$ reflections were caused by superimposition of the diffractions from the $\beta^{\prime \prime}$ and $\beta^{\prime}$ phases in these positions. This means that it is difficult to confirm the coexistence of $\beta^{\prime \prime}$ and $\beta^{\prime}$ phases by means of the SAEDP at 


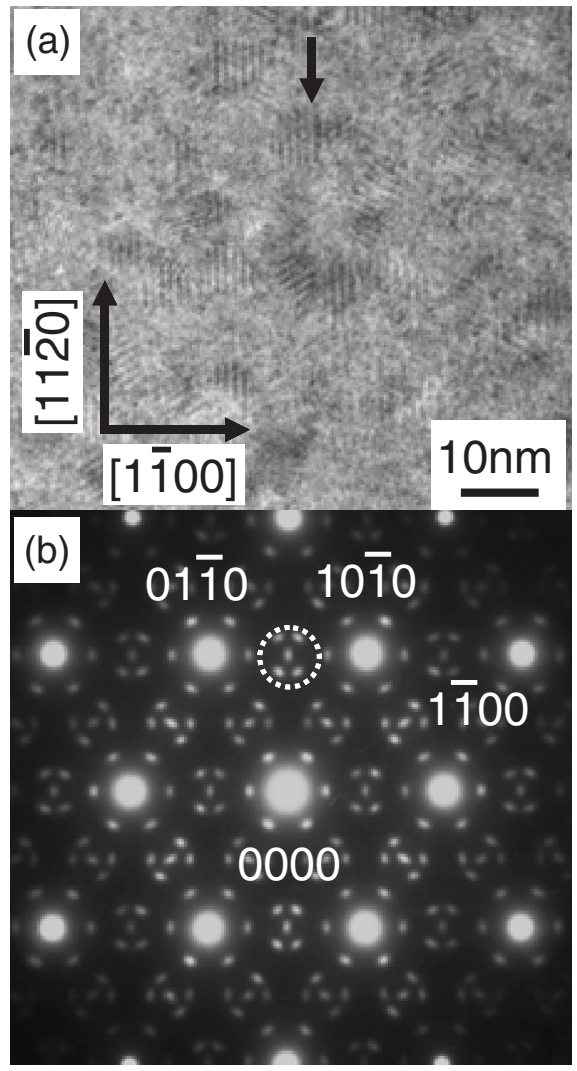

Fig. 4 TEM images of a specimen aged for $460.8 \mathrm{ks}$ at $473 \mathrm{~K}$. (a) brightfield image; an arrow shows a precipitate. (b) SAED pattern; the small five diffraction spots corresponding to the $\beta^{\prime}$ phase are indicated in a dashed circle.

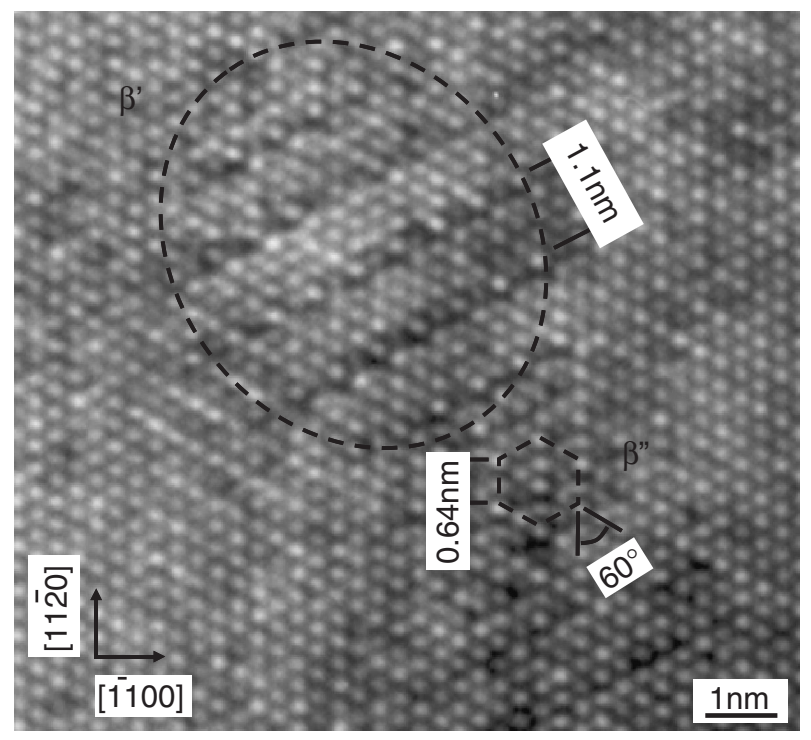

Fig. 5 HRTEM image of the specimen aged for $460.8 \mathrm{ks}$ at $473 \mathrm{~K}$. The contrasts of the $\beta^{\prime}$ and $\beta^{\prime \prime}$ phases are indicated in the solid dotted spheroid and hexagon respectively.

this stage. HRTEM observations are therefore important in confirming the existence of the $\beta^{\prime \prime}$ phase. Figure 5 shows the HRTEM image of a specimen aged under the same aging conditions as those of the specimen shown in Fig. 4. In the dashed hexagon, the hexagonal periodicity of the $\beta^{\prime \prime}$ phase was confirmed at this stage of aging. The region indicated by

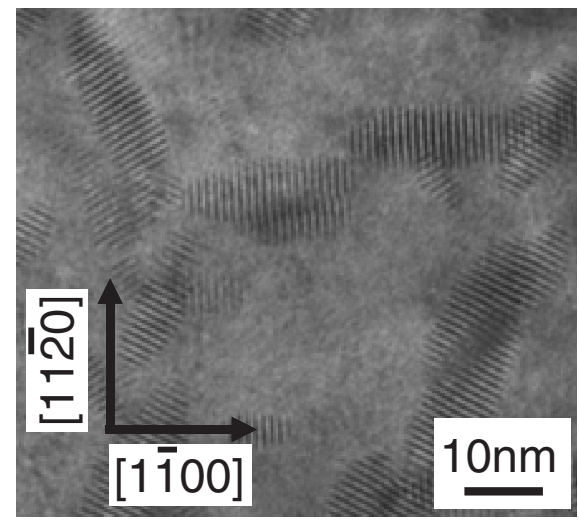

Fig. 6 TEM image of a specimen aged for $1843.2 \mathrm{ks}$ at $473 \mathrm{~K}$.

the dashed circle corresponds to a spherical precipitate with an internal fringe. In this HRTEM image, a spacing of $1.1 \mathrm{~nm}$ was observed, which corresponds to the spacing of the internal fringe in the $\beta^{\prime}$ phase. ${ }^{11)}$ It was also confirmed that the $\beta^{\prime}$ phase coexists with a small amount of the $\beta^{\prime \prime}$ phase under the condition of aging corresponding to the peak hardness. When the specimen was over-aged at $473 \mathrm{~K}$ for $1843.2 \mathrm{ks}$, the spheroidal contrasts of the $\beta^{\prime}$ phase became longer along the $\langle 1 \overline{1} 00\rangle_{\mathrm{Mg}}$ direction, as shown in Fig. 6, and this morphology is similar to the $\beta^{\prime}$ phase observed in the Mg-Gd alloy. ${ }^{12)}$

Our TEM and HRTEM observations have therefore clearly confirmed that a precursor of the $\beta^{\prime \prime}$ phase is present in the first stage of age hardening and that the $\beta^{\prime \prime}$ and $\beta^{\prime}$ phases coexist in the second stage of aging of the $\mathrm{Mg}-\mathrm{Gd}-\mathrm{Sc}$ alloy. These phases contribute to the two-stage age-hardening behavior.

\section{Conclusions}

We investigated changes in the microstructure of the $\mathrm{Mg}-$ 15 mass \%Gd-6.4 mass\%Sc alloy aged at $473 \mathrm{~K}$ in detail by means of HRTEM. The results can be summarized as follows.

(1) Hardening behavior occurred as a two-stage in the early stage of aging was confirmed in the $\mathrm{Mg}-\mathrm{Gd}-\mathrm{Sc}$ alloy, similar to that in $\mathrm{Mg}-\mathrm{Gd}$ alloys.

(2) In the first stage of age hardening, a contrast with a hexagonal arrangement of bright and dark dots with a spacing of $0.64 \mathrm{~nm}$ was observed by HRTEM, and this was assigned to a precursor of the $\beta^{\prime \prime}$ phase. This precursor of the $\beta^{\prime \prime}$ phases was the predominant phase at this stage. The $\beta^{\prime \prime}$ and $\beta^{\prime}$ phases do not coexist in the $\mathrm{Mg}-\mathrm{Gd}-\mathrm{Sc}$ alloy, unlike the case for the $\mathrm{Mg}-\mathrm{Gd}-\mathrm{Y}-\mathrm{Zr}$ alloys.

(3) In the second stage of age hardening, the HRTEM images confirmed that the $\beta^{\prime \prime}$ and $\beta^{\prime}$ phases coexisted up to the peak hardness, although it was difficult to recognize the existence of both these phases by SAEDP because of the superimposition of diffractions from the $\beta^{\prime \prime}$ and $\beta^{\prime}$ phases. The $\beta^{\prime}$ phase was observed as a nearly spherical precipitate with an array of internal fringes and a spacing of about $1.1 \mathrm{~nm}$.

(4) The $\beta^{\prime}$ phase became longer along to $\langle 1 \overline{1} 00\rangle_{\mathrm{Mg}}$ directions at the over-aging stage. 


\section{REFERENCES}

1) I. J. Polmear: Light Alloys: Metallurgy of the Light Metals, 3rd ed. (Arnold, London, 1995) pp. 231-232.

2) S. Kamado, S. Iwasawa, K. Ohuchi, Y. Kojima and R. Ninomiya: J. Jpn. Inst. Light Met. 42 (1992) 727-733.

3) S. Iwasawa, Y. Negishi, S. Kamado, Y. Kojima and R. Ryuji: J. Jpn. Inst. Light Met. 44 (1994) 3-7.

4) Y. Negishi, T. Nishimura, S. Iwasawa, S. Kamado, Y. Kojima and R. Ryuji: J. Jpn. Inst. Light Met. 44 (1994) 555-561.

5) P. Vostry, B. Smola, I. Stulikova, F. Vonbuch and B. L. Mordike: Phys. Status Solidi 175 (1999) 491-500.
6) T. Kawabata, K. Matsuda, S. Kamado, Y. Kojima and S. Ikeno: J. Jpn. Inst. Met. 70 (2006) 828-834.

7) T. Kawabata, Y. Fukuda, K. Matsuda, S. Kamado, Y. Kojima and S. Ikeno: Mater. Trans. 48 (2007) 954-959.

8) B. L. Mordike, I. Stulikova and B. Smola: Metall. Mater. Trans. A 36 (2005) 1729-1736.

9) I. Stulikova, B. Smola, F. von Buch and B. L. Mordike: Mat-wiss. u. Werkstofftech. 32 (2001) 20-24.

10) X. Gao, S. M. He, X. Q. Zeng, L. M. Peng, W. J. Ding and J. F. Nie: Mater. Sci. Eng. A 431 (2006) 322-327.

11) C. Antion, P. Donnadieu, F. Perrard, A. Deschamps, C. Tassin and A. Pisch: Acta Mater. 51 (2003) 5335-5348.

12) M. Nishijima and K. Hiraga: Mater. Trans. 48 (2007) 10-15. 